\title{
Correlation between oxidative stress and the NF- $\kappa B$ signaling pathway in the pulmonary tissues of obese asthmatic mice
}

\author{
XIAOMEI LIU, RONGJUN LIN, BAOCHUN ZHAO, RENZHENG GUAN, TANG LI and RONG JIN \\ Department of Pediatrics, The Affiliated Hospital of Qingdao University, Qingdao, Shandong 266003, P.R. China
}

Received January 29, 2015; Accepted November 17, 2015

DOI: $10.3892 / \mathrm{mmr} .2015 .4663$

\begin{abstract}
The obesity-asthma phenotype is characterized by increased asthma severity and decreased glucocorticoid responsiveness. To date, the mechanism underlying the association between obesity and asthma remain to be fully elucidated. The present study investigated the correlation between oxidative stress and the nuclear factor (NF) $-\kappa \mathrm{B}$ pathway in obese asthmatic mice. The animals were divided into the following groups: Control $(n=8)$, comprising C57BL/6J mice without exposure to a high-fat diet; non-obese asthma group $(n=8)$, comprising mice of a normal weight subjected to the induction of asthma; obese control group $(n=8)$, comprising C57BL/6J mice subjected to a high-fat diet; and obese asthmatic group $(n=8)$, comprising obese mice subject to the induction of asthma. The levels of the malondialdehyde (MDA) oxidant and glutathione (GSH) antioxidant in the lungs and bronchoalveolar lavage fluid (BALF) were measured using ELISA. The expression levels of inhibitory $\kappa \mathrm{B}$ kinase $-\beta$ (IKK- $\beta$ ) and the inhibitor of $\kappa \mathrm{B} \alpha(\mathrm{I} \kappa \mathrm{B}-\alpha)$ in the pulmonary tissues was determined using western blot analysis. An electrophoretic mobility shift assay was performed to determine the transcription activity of NF- $\kappa \mathrm{B}$. The levels of MDA in the BALF and lung tissues increased significantly in the two asthmatic groups, compared with the control groups $(\mathrm{P}<0.01)$. The asthmatic mice showed significantly lower concentrations of GSH in the BALF and lung tissues, compared with the control groups $(\mathrm{P}<0.01)$. In the asthmatic animals, the expression of I $\kappa \mathrm{B}$ kinase $(\mathrm{IKK})-\beta$ and activation of $N F-\kappa \mathrm{B}$ were upregulated in the pulmonary tissues, compared with those in the control groups $(\mathrm{P}<0.01)$. The expression of IKK- $\beta$ and transcriptional activity of $\mathrm{NF}-\kappa \mathrm{B}$ were significantly higher the in obese asthmatic mice, compared with the non-obese asthmatic mice $(\mathrm{P}<0.01)$. On examining the expression levels of
\end{abstract}

Correspondence to: Miss. Tang Li, Department of Pediatrics, The Affiliated Hospital of Qingdao University, 16 Jiangsu Road, Qingdao, Shandong 266003, P.R. China

E-mail: qddrli@163.com

Key words: obesity-asthma, oxidative stress, nuclear factor- $\kappa \mathrm{B}$ signaling pathway
$\mathrm{I} \kappa \mathrm{B}-\alpha$ in the pulmonary tissues, a significant reduction was found in the asthmatic animals, compared with the controls $(\mathrm{P}<0.01)$. In addition, the level of I $\kappa \mathrm{B}-\alpha$ was significantly lower in the obese asthmatics, compared with the non-obese asthmatics $(\mathrm{P}<0.01)$. MDA was positively correlated with $\mathrm{NF}-\kappa \mathrm{B}$ in the obese asthmatic group $(\mathrm{R}=0.83 ; \mathrm{P}<0.05)$ and non-obese asthmatic group $(\mathrm{R}=0.82 ; \mathrm{P}<0.05)$. Oxidative stress was upregulated in the pulmonary tissues of the asthmatic mice. This upregulation was more marked in the obese asthmatic mice, and was positively correlated with activation of the $\mathrm{NF}-\kappa \mathrm{B}$ signaling pathway in the pulmonary tissues. The results in the present study indicated that higher oxidative stress and activation of the $N F-\kappa B$ signaling pathway were observed in the lung tissues of the obese asthmatics. Furthermore, a positive correlation was identified between oxidative stress and $\mathrm{NF}-\kappa \mathrm{B}$.

\section{Introduction}

Asthma is a chronic inflammatory airway disease. Several factors have been considered to be associated with the pathogenesis of asthma, among which obesity has been considered as an independent risk factor (1). Accumulating evidence indicates that an imbalance between the production of reactive oxygen species (ROS) and antioxidant defenses, favoring a more oxidative state, is present in asthma or obesity $(2,3)$. For example, in patients with asthma or obesity, the elevation of oxidative stress and changes in antioxidant defenses have been reported $(2,4)$. However, the potential mechanism underlying the association between obesity and asthma remain to be fully elucidated.

Increasing attention has been focussed on the role of oxidative stress in obese patients with asthma. According to a previous study, increased systemic or airway oxidative stress may be a potential cause for increased severity in the co-occurrence of obesity and asthma (5). Albuali reported that the serum level of malondialdehyde (MDA), a biomarker of oxidative stress, is markedly increased in obese children, compared with a normal control group, whereas the serum levels of glutathione (GSH), an antioxidants, is decreased (4). In addition, body mass index (BMI) has been found to be associated with exhaled 8-isoprostanes, another biomarker of oxidative stress, in asthmatics (5). Johnson et al reported that calorie restriction contributed to the reduction of oxidative stress in obese patients with asthma by weight loss (6). These 
previous reports indicate the requirement to investigate the mechanism underlying the involvement of oxidative stress in the obesity-asthma association.

Nuclear factor (NF) $-\kappa \mathrm{B}$, a redox-sensitive factor, has been considered to be closely associated with oxidative stress (7). Of note, a vicious cycle has been reported between the $\mathrm{NF}-\kappa \mathrm{B}$ pathway and oxidative stress. Oxidative stress is crucial in the activation of the $\mathrm{NF}-\kappa \mathrm{B}$ signaling pathway, however, several inflammatory cytokines are produced following activation of this pathway, resulting in the aggravation of oxidative stress (8). NF- $\kappa \mathrm{B}$ has been considered to be critical in the pathophysiology of asthma, as it can modulate the majority of the inflammatory cytokines involved in the pathogenesis of asthma, including intercellular adhesion molecule-1, tumor necrosis factor- $\alpha$ and interleukin-8 (9). For example, Lee et al reported that the levels of ROS and NF- $\kappa \mathrm{B}$ levels were increased in a murine model of asthma, and that ROS upregulated the

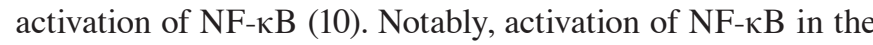
whole body was reported in obese fed a high-fat diet (11). In addition, Pierce et al reported that NF- $\mathrm{NB}$ is important in the modulation of patients with obesity-associated vascular endothelial dysfunction, partly via stimulating oxidative stress (12). However, few reports are available investigating the association between the $\mathrm{NF}-\kappa \mathrm{B}$ pathway and oxidative stress in the obesity-asthma association.

In the present study, an obesity-asthma mouse model was established, based on which the correlation between oxidative stress and the NF- $\mathrm{NB}$ pathway was investigated. The aim was to determine whether oxidative stress was upregulated in the pulmonary tissues of the obese asthmatic mice, and whether oxidative stress was correlated with activation of the $\mathrm{NF}-\kappa \mathrm{B}$ signaling pathway in the pulmonary tissues.

\section{Materials and methods}

Animals. Female C57BL/6J mice of specific-pathogen-free grade (3-4 weeks old, weighing 16 $\pm 1.6 \mathrm{~g}$ ) were purchased from the Shanghai Laboratory Animal Center (Shanghai, China). The animals were housed and fed in the Animal Laboratory Center of Qingdao University (Qingdao, China) for adaptation for 1 week, in a chamber at a temperature of $25^{\circ} \mathrm{C}$ and with a humidity of $60 \%$, a $12 \mathrm{~h}$ light- $12 \mathrm{~h}$ dark cycle and free access to food and water. All protocols used in the present study are approved by the ethics committee of the Affiliated Hospital of Qingdao University.

Preparation of obese mice. The mice were fed with a high fat diet (45\% energy; D12451; Research Diets, New Brunswick, NJ, USA) ad libitum for 12 weeks. The body weight of the animals was monitored every week. Obese mice were defined as those with a body weight $>20 \%$ higher, compared with the baseline weight. The animals, which were not designated as obese were excluded from further investigations.

Experimental design. The animals were divided into the four following groups: Control group $(\mathrm{n}=8)$, comprising C57BL/6J mice with a normal diet; non-obese asthma group $(n=8)$, comprising C57BL/6J mice with a normal weight subjected to the induction of asthma; obese control group $(n=8)$, comprising obese C57BL/6J mice subjected to a high-fat diet; and obese asthmatic group $(n=8)$, comprising obese mice subjected to the induction of asthma.

For the induction of asthma, the animals in the non-obese asthma group $(n=8)$ and obese asthmatic group $(n=8)$ were immunized with an intra-peritoneal injection of $25 \mu \mathrm{g}$ ovalbumin (Sigma-Aldrich, St. Louis, MO, USA) and $1 \mathrm{mg}$ aluminum hydroxide (Sigma-Aldrich) on day 1 of weeks 13, 14 and 15 , respectively. Subsequently, $2 \%$ ovalbumin was administered via atomization at week 16 for $30 \mathrm{~min}$ per day, followed by atomization every other day in weeks 17, 18 and 19, respectively. The animals in the control $(n=8)$ and obese control group $(n=8)$ were treated at the same time points, using phosphate-buffered saline (PBS; Shanghai Institute of Biotechnology Co., Ltd, Shanghai, China).

At $\sim 24 \mathrm{~h}$ during the final challenge, anesthesia was performed using $10 \%$ chloral hydrate $(0.004 \mathrm{ml} / \mathrm{kg}$ body weight), followed by cervical dislocation to sacrifice the mice. Subsequently, thoracotomy was performed, based on which the trachea and primary bronchus were exposed, and the left lung was lavaged twice using 0.5 ml PBS. The bronchoalveolar lavage fluid (BALF) was centrifuged at $1,000 \mathrm{rpm}(433 \mathrm{x} \mathrm{g})$ for $10 \mathrm{~min}$ at $4^{\circ} \mathrm{C}$. The resulting pellet was suspended in PBS, and the cytological classification was performed by microscopy, using an Olympus CX21 microscope (Olympus, Tokyo, Japan) with a magnification of 100x. Each slice was selected for each mouse, and 200 cells were randomly selected from four regions to record the cell count. For Giemsa staining, two or three drops of resuspension solution of BALF were spread onto the microscope slides, heat-fixed, stained with Giemsa stain for $10 \mathrm{~min}$, and subsequently washed under running tap-water for $2 \mathrm{~min}$. The lung tissues were fixed, and hematoxylin staining was performed as previously described (10).

Determination of levels of MDA and GSH in pulmonary tissues and BALF. Following homogenization of the frozen pulmonary tissues at $0^{\circ} \mathrm{C}$ in an ice water bath, the mixture was centrifuged at $3,000 \mathrm{~g}$ for $10 \mathrm{~min}$ at $4^{\circ} \mathrm{C}$. Subsequently, the supernatant was obtained, and the concentrations of MDA and GSH in the supernatant and BALF were determined using an ELISA assay. The ELISA kits (for MDA, cat. no. m198012; for GSH, cat. no. m1027889) were purchased from Mlbio Co., Ltd., Shanghai, China), and the ELISA assay was performed according to the manufacturer's protocol. The micro-plate 550 reader was purchased from Bio-Rad Laboratories (Shanghai, China). The quantity of the supernatant was $100 \mu \mathrm{l}$, and the wavelength was set at $450 \mathrm{~nm}$.

BALF cytological classification and histological evaluation. For the cytological classification of the BALF, the number of cells were counted independently by two investigators, in a blinded-manner, using a CX21 Olympus microscope. In total, four fields were randomly-selected, and 200 cells were counted in each of the fields. Histological examination was performed using specific scoring criteria previously described by Lee et al (13). The grade of inflammation was scored at the same time by the two investigators. The level of peribronchial and perivascular inflammation was evaluated subjectively, according to a previous report (13), in which a value of 0 represented no inflammation, 1 represented occasional inflammatory 
Table I. Cell counts in the bronchoalveolar lavage fluid of the control and experimental groups.

\begin{tabular}{|c|c|c|c|c|}
\hline \multirow[b]{2}{*}{ Cell (type) } & \multicolumn{4}{|c|}{ Experimental group } \\
\hline & Obese control & Control & Obese asthma & Non-obese asthma \\
\hline Total cells $\left(\times 10^{4} / \mathrm{ml}\right)$ & $10.37 \pm 0.70$ & $6.50 \pm 0.53$ & $213 \pm 8.40^{\mathrm{b}}$ & $132 \pm 4.90$ \\
\hline \multicolumn{5}{|l|}{ Cell type } \\
\hline Eosinophils ${ }^{\mathrm{a}}$ & $1.62 \pm 0.18$ & $1.62 \pm 0.18$ & $42.37 \pm 1.46^{\mathrm{b}}$ & $61.00 \pm 2.50$ \\
\hline Neutrophils $^{\mathrm{a}}$ & $8.75 \pm 1.17$ & $7.25 \pm 1.19$ & $47.60 \pm 1.94^{\mathrm{b}}$ & $32.37 \pm 1.17$ \\
\hline Macrophages $^{\mathrm{a}}$ & $146 \pm 1.93$ & $150 \pm 2.59$ & $69.25 \pm 1.61$ & $63.00 \pm 3.64$ \\
\hline Lymphocytes $^{\mathrm{a}}$ & $42.75 \pm 1.84$ & $41.12 \pm 1.94$ & $40.75 \pm 1.37$ & $43.62 \pm 1.71$ \\
\hline
\end{tabular}

Values are expressed as the mean \pm standard error of the mean. ${ }^{\text {TT }}$ The numbers of eosinophils, neutrophils, macrophages and lymphocytes reported are per 200 cells. ${ }^{b} \mathrm{P}<0.01$ vs. the obese control, control and non-obese asthma groups.

cells, 2 represented bronchi or vessels surrounded by folium (1-5 cells) of inflammatory cells, and 3 represented a thick layer of inflammatory cells ( $>5$ cells) surrounding the bronchi or the vessels.

Western blot analysis. The pulmonary tissues (100 mg) were homogenized in radioimmunoprecipitation assay lysis buffer (Mlbio Co., Ltd.; cat. no ml16963) containing protease and phosphatase inhibitors. The Bradford method was used for protein quantification. A total of $10 \mu \mathrm{g}$ proteins were separated by electrophoresis on a $10 \%$ SDS-PAGE gel using an SDS-PAGE Gel Preparation kit (cat. no. KGP113; Shanghai Institute of Biotechnology Co., Ltd.), and the samples were subsequently electro-transferred onto a nitrocellulose filter (cat. no. nc-b102; Jieyi Biotech, Shanghai, China) at a current of $200 \mathrm{~mA}$ for $2 \mathrm{~h}$. Subsequently, the membrane was blocked using 5\% non-fat milk and incubated with the primary antibodies against inhibitory $\kappa \mathrm{B}$ kinase- $\beta$ (rabbit monoclonal antibody IKK- $\beta$; cat. no. 2370, 1:1,000; Cell Signaling Technology, Inc. Danvers, MA, USA) and the inhibitor of $\kappa \mathrm{B} \alpha$ (rabbit monoclonal antibody IкB- $\alpha$; cat. no. 4812, 1:1,000; Cell Signaling Technology, Inc.) at $4^{\circ} \mathrm{C}$ overnight. Following incubation, the membrane was incubated with peroxidase-conjugated, goat anti-rabbit secondary antibodies (1:1,000; Cell Signaling Technology, Inc.) for $1 \mathrm{~h}$ at room temperature. The membranes were washed with PBS. The same membrane, loaded with $\beta$-actin, served as a control. The relative density of IKK- $\beta$ and $\mathrm{I} \kappa \mathrm{B}-\alpha$ to $\beta$-actin was evaluated using Gel-Pro32 software (Syngene, Inc., San Diego, CA, USA).

Electrophoretic mobility shift assay (EMSA). To determine the binding activity between $\mathrm{NF}-\kappa \mathrm{B}$ and DNA, an EMSA was performed, as previously described (14). In brief, the nuclear protein was extracted from the pulmonary tissues using commercial kits (KeyGen Biotech Co., Ltd., Nanjing, China), according to the manufacturer's protocol. The protein concentration was determined using the Bradford method. Subsequently, a biotin-labeled NF- $\kappa$ B probe (Pierce Biotechnology, Inc., Rockford, IL, USA) was incubated with the nuclear protein at $15-20^{\circ} \mathrm{C}$ for $30 \mathrm{~min}$. The products were then separated by electrophoresis on a $6 \%$ non-denaturing polyacrylamide gel (Invitrogen; Thermo Fisher Scientific,
Inc., Shanghai, China). The competition experiment was performed through the addition of a 100 -fold solution of unlabeled probe (Pierce Biotechnology, Inc.), following which the biotin-labeled probe (Pierce Biotechnology, Inc.) was added to the reaction. Finally, the relative density of the probe was evaluated using Gel-Pro32 software (Syngene, Inc.).

Statistical analysis. All data are presented as the mean \pm standard error of the mean. SPSS 17.0 was used for the statistical analyses (SPSS, Inc., Chicago, IL, USA). One-way analysis of variance was used to compare inter-group differences. The significance of correlations was evaluated using Pearson's correlation coefficient. $\mathrm{P}<0.05$ was considered to indicate a statistically significant difference.

\section{Results}

Acute symptoms induced by asthmatic attack. Following the induction of asthma, the animals showed dysphoria or a state of motionless, tachypnea, nodding respiration, reduced erection and forelimb shrinkage, as well as urinary and fecal incontinence. However, in the normal control group and obese control group, no such symptoms were observed.

Total cell count and cytological classification in BALF. A significant increase in the total cell count was found in the BALF from the non-obese and obese asthmatic groups, compared with the control and obese control groups $(\mathrm{P}<0.01$; Table I), in which only a small number of cells were observed. Regarding the number of eosinophils and neutrophils, the number of these cells showed a marked increase in the two asthmatic groups, compared with the control groups $(\mathrm{P}<0.01)$. However, the number of neutrophils was higher $(\mathrm{P}<0.01)$, and the number of eosinophils was lower $(\mathrm{P}<0.01)$ in the obese asthmatic mice, compared with the levels in the non-obese asthmatic group. No statistical difference was observed between the two control groups $(\mathrm{P}>0.05)$.

Pathological variation in lung tissues. In the non-obese control group, the bronchioles and alveolar were clear with no inflammatory cell infiltration. In the obese control group, a reduction in inflammatory cell infiltration was observed. 
A

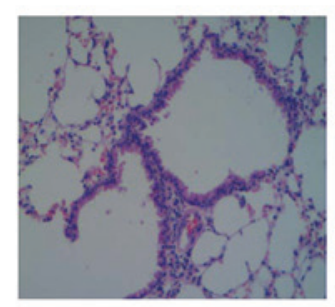

Obese control

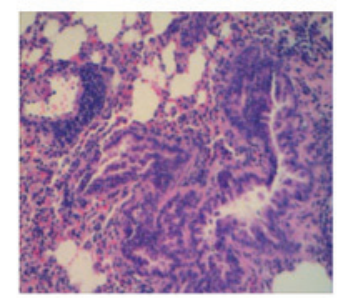

Obese asthma

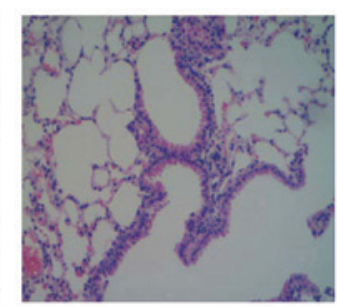

Control

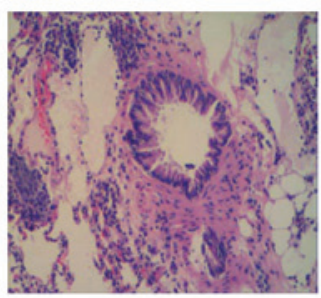

Non-obese asthma
B

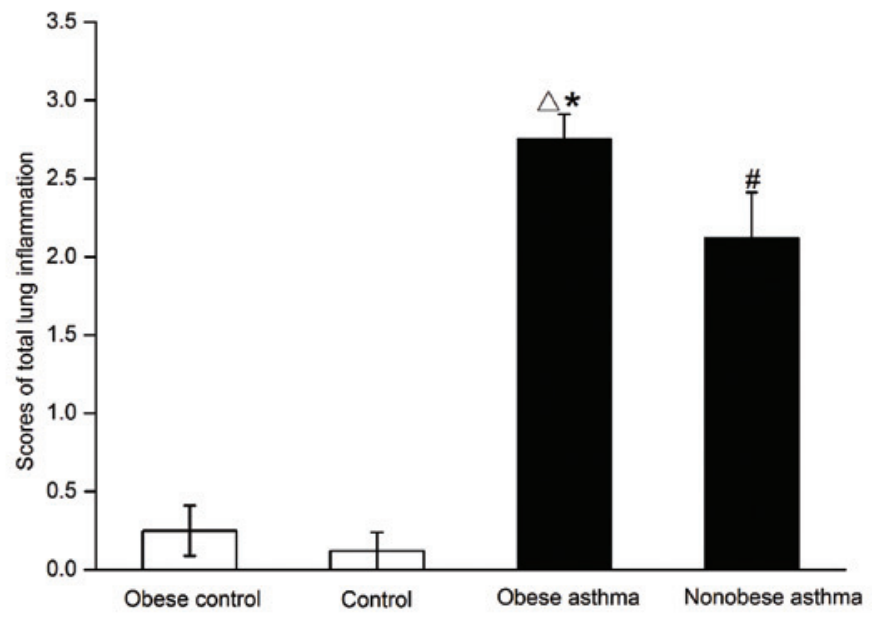

Figure 1. Pathological analyses of the pulmonary tissues from mice in the control and experimental groups. (A) Hematoxylin and eosin staining images are shown (magnification, x200). A marked infiltration of inflammatory cells was observed in the obese asthmatic animals. (B) Summary of the scores in lung inflammation. The scores were assigned as follows: 0 , no inflammation; 1 , occasional inflammatory cells; 2 , bronchi or vessels surrounded by folium (1-5 cells) of inflammatory cells; 3 , thick layer of inflammatory cells ( $>5$ cells) surrounding the bronchi or vessels. Data are presented as the mean \pm standard error of the mean. ${ }^{\Delta} \mathrm{P}<0.01$, obese asthma vs. obese control and control; ${ }^{*} \mathrm{P}<0.01$, non-obese asthma vs. obese control and control; ${ }^{*} \mathrm{P}<0.05$, obese asthma vs. non-obese asthma.

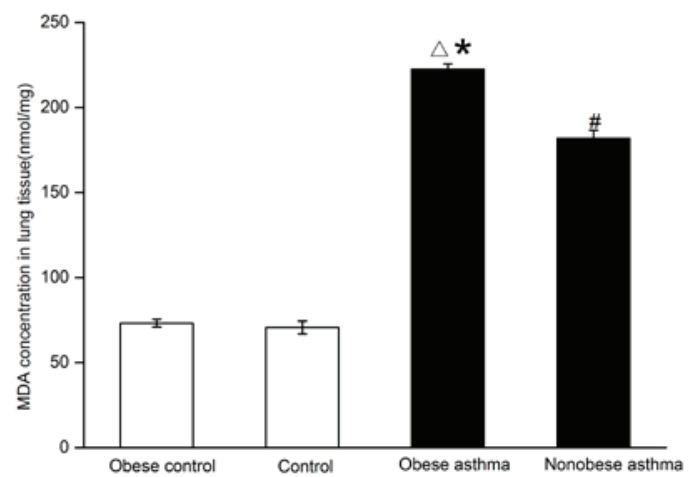

C

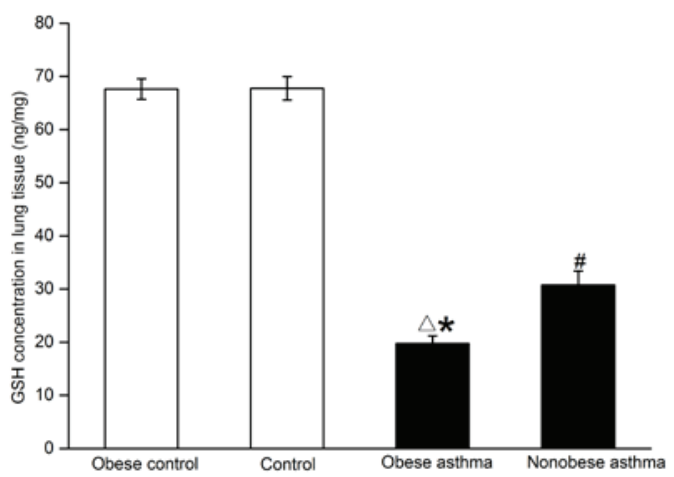

B

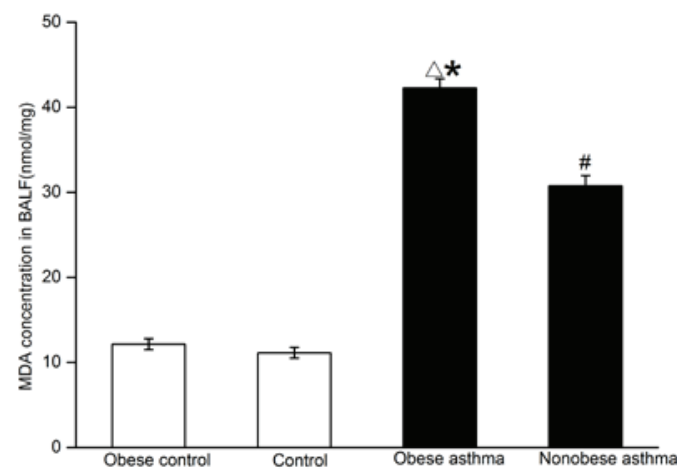

D

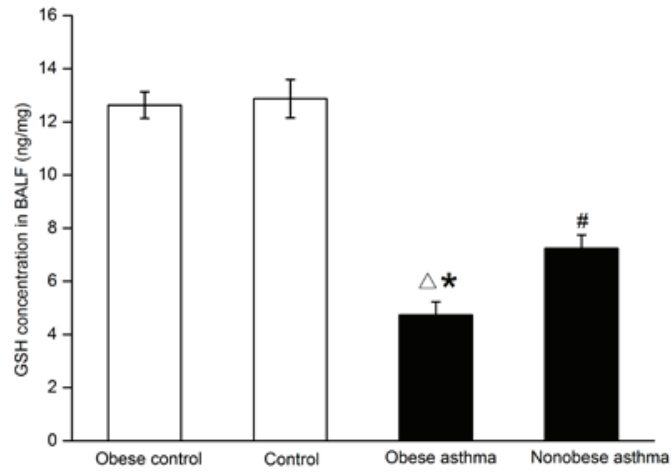

Figure 2. Determination of the levels of MDA in (A) lung tissues and (B) BALF, and levels of GSH in (C) lung tissues and (D) BALF. Data are presented as the mean \pm standard error of the mean. (A and $\mathrm{B}$ ) ${ }^{\triangle} \mathrm{P}<0.01$, obese asthma vs. obese control and control; ${ }^{*} \mathrm{P}<0.01$, non-obese asthma vs. obese control and control; ${ }^{*} \mathrm{P}<0.01$, obese asthma vs. non-obese asthma. (C and D) ${ }^{\triangle} \mathrm{P}<0.01$, obese asthma vs. obese control and control; ${ }^{*} \mathrm{P}<0.01$, non-obese asthma vs. obese control and control; "P<0.05, obese asthma vs. non-obese asthma. MDA, malondialdehyde; GSH, glutathione; BALF, bronchoalveolar lavage fluid.

In the non-obese asthma group, the significant infiltration of inflammatory cells was noted around the bronchioles, together with reduced formation of the plica mucosa, and thickening of the smooth muscle and basement membrane. In the obese asthmatic group, severe infiltration of inflammatory cells was observed, together with rupture of the mucous 
A

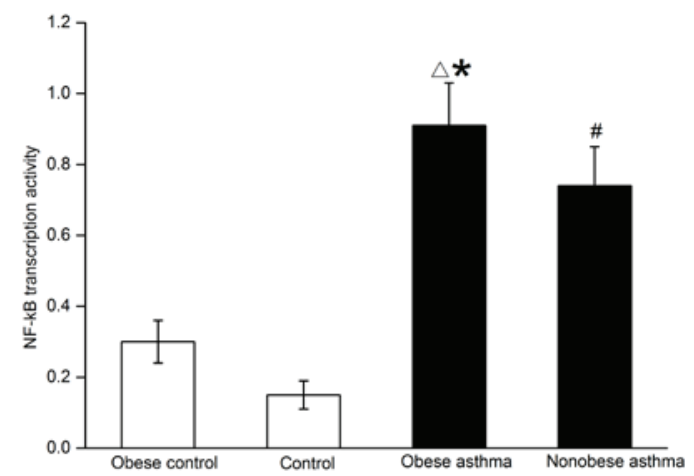

B

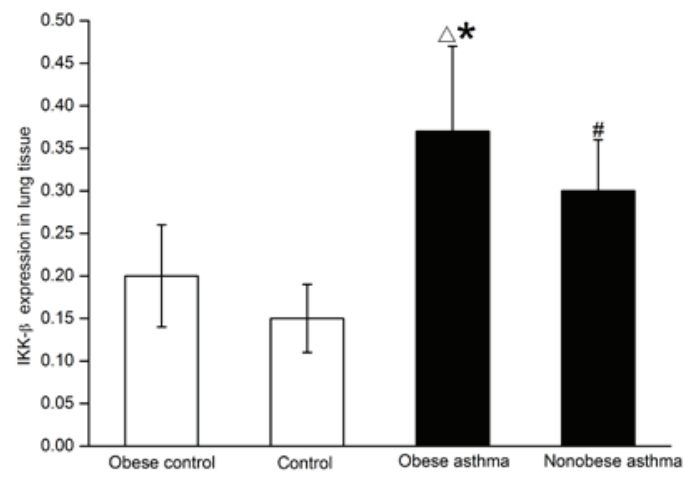

C

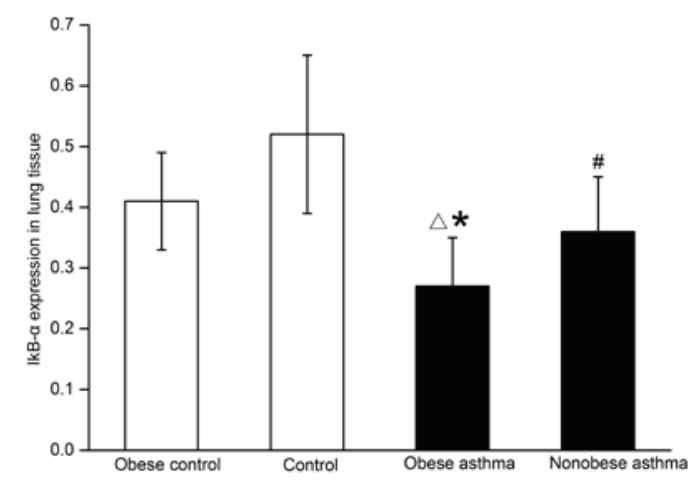

Figure 3. Determination of (A) NF- $\kappa$ B transcription activity and (B) expression of IKK- $\beta$ in lung tissues, and (C) the expression level of I $\kappa-\mathrm{B}-\alpha$ in the lung tissues. Data are presented as the mean \pm standard error of the mean. ${ }^{\wedge} \mathrm{P}<0.01$, obese asthma vs. obese control and control; ${ }^{\#} \mathrm{P}<0.01$, non-obese asthma vs. obese control and control; ${ }^{2} \mathrm{P}<0.01$, obese asthma vs. non-obese asthma. NF- $\kappa \mathrm{B}$, nuclear factor- $\kappa \mathrm{B}$; IKK, I $\mathrm{B}$ kinase.

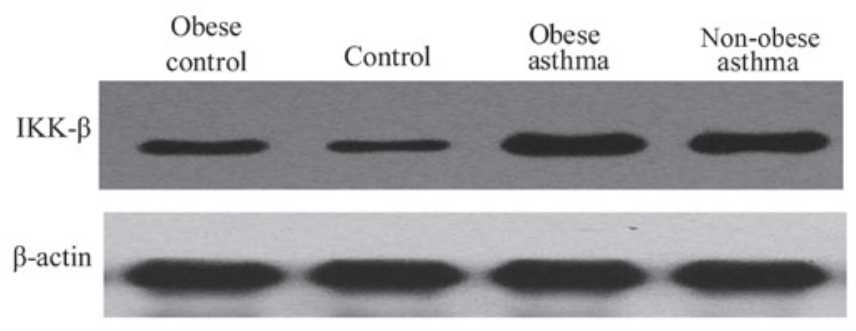

Figure 4. Expression levels of IKK- $\beta$ were determined using western blot analysis. $\beta$-actin served as a control. IKK, ІкB kinase.

membrane and smooth muscle, and alveolar fusion (Fig. 1A and B).

Concentrations of MDA and GSH in BALF and lung tissue. The concentrations of MDA in the BALF and lung tissues showed significant increases in the two asthmatic groups, compared with the control groups $(\mathrm{P}<0.01$; Fig. $2 \mathrm{~A}$ and $\mathrm{B})$. Their levels were comparatively higher in the obese asthmatic group, compared with those in the non-obese asthmatic group $(\mathrm{P}<0.01)$. These results indicated the presence of oxidative stress in the airway and lung tissue of asthmatics, which was even more marked in the obese asthmatic mice. No significant difference was observed in the levels of MDA in the two control groups $(\mathrm{P}>0.05)$.

Asthmatic mice had significantly lower BALF and lung tissue concentrations of GSH, compared with the control group, respectively $(\mathrm{P}<0.01$; Fig. $2 \mathrm{C}$ and $\mathrm{D})$. In addition, the concentration of GSH was significantly lower in the obese asthmatic mice, compared with that in the non-obese asthmatic mice $(\mathrm{P}<0.05)$. On this basis, it was clear that the decrease in antioxidant defenses was more marked in the obese asthmatic mice. No significant differences was observed between two control groups $(\mathrm{P}>0.05)$.

Expression levels of $I K K-\beta$ and $I_{\kappa} B-\alpha$, and the transcriptional activity of $N F-\kappa B$ in pulmonary tissues. In the asthmatic animals, the expression of IKK- $\beta$ and transcriptional activity $\mathrm{NF}-\kappa \mathrm{B}$ were upregulated in the pulmonary tissues, compare with the pulmonary tissues obtained from the control groups $(\mathrm{P}<0.01$; Fig. 3A and $\mathrm{B})$. By contrast, a significant reduction in the expression of I $\mathrm{B}-\alpha$ was observed in the asthmatic animals, compared with the control animals $(\mathrm{P}<0.01$; Fig. $3 \mathrm{C})$. The expression of IKK- $\beta$ and transcriptional activity of $\mathrm{NF}-\kappa \mathrm{B}$ were significantly higher in the obese asthmatic mice, compared with the non-obese asthmatic mice $(\mathrm{P}<0.01$; Figs. 4 and 5). In addition, compared with the normal control, the expression of IKK- $\beta$ and transcriptional activity of $N F-\kappa B$ in the lung tissues of the obese control were higher $(\mathrm{P}<0.01)$. In the obese asthmatic group, the level of I $\mathrm{B}-\alpha$ was significantly lower, compared with those observed in the non-obese asthmatic group $(\mathrm{P}<0.01$; Fig. 6). In the control groups, the expression levels of I $\kappa \mathrm{B}-\alpha$ were lower in the obese animals, compared with the non-obese animals $(\mathrm{P}<0.01)$.

Association between the concentration of MDA and transcriptional activity of $N F-\kappa B$ in pulmonary tissues. To investigate 


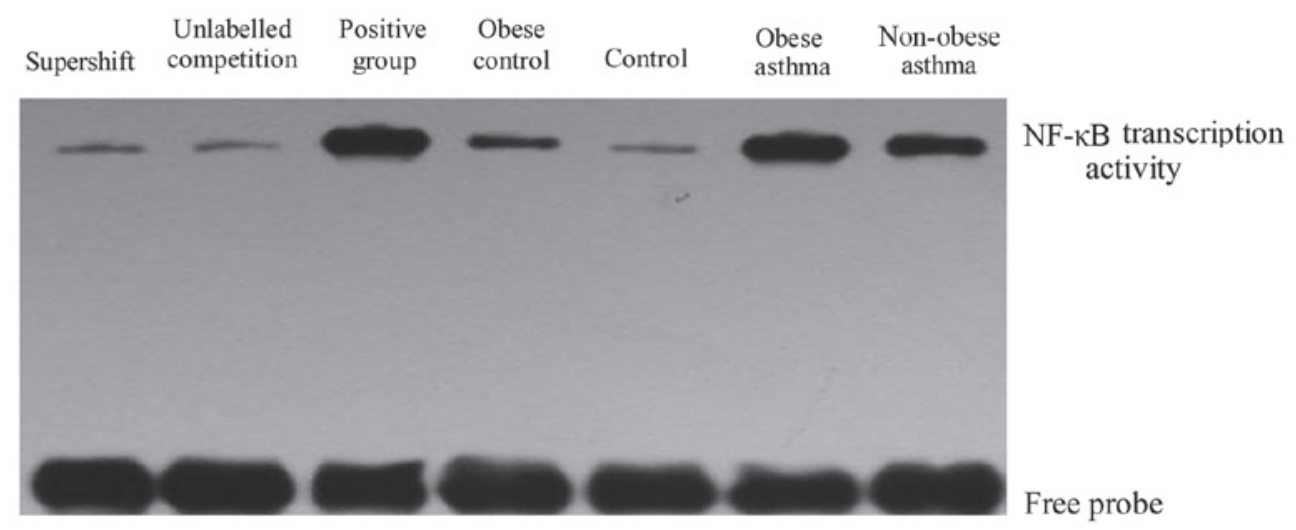

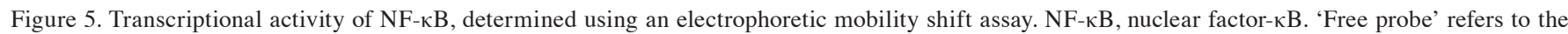
probe not bound to NF- $\mathrm{kB}$.

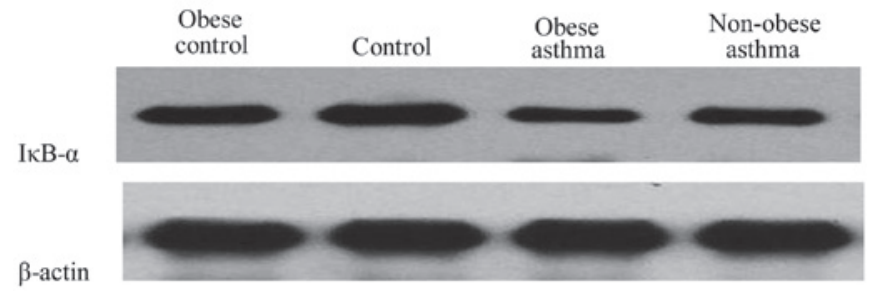

Figure 6. Expression levels of IкB- $\alpha$ were determined using Western blot analysis. $\beta$-actin served as a control.

the potential link between oxidative stress and the NF- $\mathrm{KB}$ signaling pathway, the present study determined the MDA ( $\log$ ) concentration and transcriptional activity of NF- $\kappa \mathrm{B}$ using linear correlation analysis. The results showed that MDA was positively correlated with NF- $\mathrm{KB}$ in the obese asthmatic group $(\mathrm{R}=0.83 ; \mathrm{P}<0.05)$ and the non-obese asthmatic group $(\mathrm{R}=0.82$; $\mathrm{P}<0.05$ ). However, no correlation was identified between MDA and NF- $\kappa \mathrm{B}$ in either control group.

\section{Discussion}

Compared with the non-obese asthmatic mice, the clinical signs were more severe in the obese asthmatic group in the present study. In addition, the number of neutrophils was higher in the BALF obtained from the obese asthmatic mice. Furthermore, the concentrations of MDA in the pulmonary tissues and the BALF were higher in the asthmatic mice, compared with the control mice, and the level of MDA in the obese asthmatic mice was higher, compared with that in the non-obese asthmatic mice. In the present study, the activation of the NF-кB pathway in the pulmonary tissues was examined, and the results indicated that the pathway was significantly upregulated in the asthmatic mice, compared with the control mice. Additionally, the activation of the pathway was more marked in the obese asthmatic mice, compared with that in the non-obese asthmatic mice. In the two asthmatic groups, the activation of NF- $\mathrm{kB}$ was positively correlated with oxidative stress in the pulmonary tissues. Furthermore, the signs in the obese asthmatic mice were more severe, compared with those in the non-obese asthmatic mice, which may be associated with the enhanced oxidative stress and activation of NF- $\mathrm{KB}$ pathway in the pulmonary tissues.

It is known that an increase in ROS levels is direct evidence of oxidative stress, however, it is difficult to detect the generation of ROS directly (15). According to a previous study, the increased generation of ROS in asthma can cause damage to a wide range of biological molecules (16). Systemic oxidative stress is elevated in asthmatic patients, which is characterized by increased levels of protein carbonyls and products of lipid peroxidation in the plasma (17). MDA is a product of lipid peroxidation and is also a credible biomarker of oxidative stress. Exhaled breath condensate levels of MDA are increased in asthmatic children (18), and concentrations of MDA are elevated in blood samples from obese patients, which indicate an increase of systemic oxidative stress (4). However, few studies have been performed to investigate airway or lung levels of MDA in obesity or obesity co-occurring with asthma. In the present study, the levels of MDA in the lung and BALF, were determined, which revealed that the levels of MDA in the pulmonary tissues and BALF from the asthmatic mice were significantly higher than those in the controls. No statistical difference was noted in the levels of MDA between the obese control and normal control groups. Furthermore, compared with the non-obese asthma group, the generation of MDA in the obese asthmatic group was markedly increased $(\mathrm{P}<0.01)$. Another marker of oxidative stress, 8 -isoprostanes, is a product of lipid peroxidation. In a previous study, analysis of the production exhaled 8-isoprostanes revealed that local oxidative stress in the airway was not associated with BMI in healthy non-asthmatic controls (19). By contrast, another study reported that exhaled 8-isoprostanes was significantly increased in patients with simple obesity (15). These results reflect controversies in the association between airway levels of local oxidative stress and simple obesity. Increasing evidence indicates that local oxidative stress in the airways of obese asthmatic patients is significantly higher, compared with that in asthmatic patients of normal weight. For example, a previous study reported that obesity was associated with increased exhaled 8-isoprostane in asthmatics and controls (15), and Komakula et al reported that BMI was associated with an increase in the levels of exhaled 8-isoprostanes in adults with moderate to severe persistent asthma, compared with controls (5). However, the mechanisms underlying the 
association between obesity and the levels of local oxidative stress in the airways in asthma remains to be elucidated.

Several enzymatic and nonenzymatic antioxidants are involved in protective effects in the blood and lungs, including GSH peroxidase (GPx), superoxide dismutase (SOD), catalase and GSH (20). It has been well acknowledged that GSH is important in the antioxidant defenses of the lung to counter oxidant-mediated toxicity (21). Aberrant changes in antioxidant defenses have been reported in asthmatic patients. Decreased levels of GSH in erythrocytes have been reported in patients with mild asthma, compared with healthy controls (22). In addition, the mean levels of GSH-Px in red blood cells are reduced in asthmatic patients (17). SOD activity is also increased in the BAL of asthmatics (23). Of note, studies have reported aberrant changes in antioxidant defenses in patients with simple obesity. For example, the erythrocyte activities of SOD, CAT, GSH-Px and GSH were decreased in obese children, compared with those in individuals of a normal weight (4). To our best knowledge, few studies have been performed to investigate the antioxidant defenses in obese patients with asthma. In the present study, it was confirmed that GSH was significantly decreased in the lung tissues and BLAF in obese asthmatic mice, compared with non-obese asthmatic mice $(\mathrm{P}<0.05)$. This may be one of the reasons for increase in asthma signs/symptoms.

The roles of the NF- $\kappa$ B pathway in the pathology of asthma and obesity have been well confirmed $(10,11)$. Previous studies have shown that NF- $\kappa \mathrm{B}$ activation is increased in peripheral blood mononuclear cells, liver and skin tissues of obese humans and animals (24-26). In asthmatic models, the mRNA expression of $\mathrm{NF}-\kappa \mathrm{B}$ has been reported to be elevated in the lung tissues of ovalbumin-induced asthmatic mice, and its expression is reduced by the administration of the antioxidant, L-2-oxothiazolidine-4-carboxylic acid (10). On this basis, the present study investigated the association between the NF- $\kappa \mathrm{B}$ pathway and oxidative stress in obese asthmatic mice. The results of the present study revealed that the transcription activity of $\mathrm{NF}-\kappa \mathrm{B}$ was upregulated in the asthmatic mice, compared with the controls. In addition, the transcriptional activity of NF- $\mathrm{NB}$ in the obese asthmatic group was higher, compared with that in the non-obese asthmatic group. In the obese control group, the activation of $\mathrm{NF}-\kappa \mathrm{B}$ was higher than in the normal control group. The concomitant increase in the expression of IKK- $\beta$ and decrease in expression of I $\mathrm{B}$ B- $\alpha$ were consistent with the observed change in $\mathrm{NF}-\kappa \mathrm{B}$, as previously described (27). In a similar study, following the objective intake of a $900 \mathrm{kcal}$ mixed meal, the expression levels of $\mathrm{NF}-\kappa \mathrm{B}, \mathrm{IKK}-\alpha$ and IKK- $\beta$ in the plasma increased significantly, the expression of I $\kappa \mathrm{B}-\alpha$ decreased and ROS generation increased in parallel, and indicated that the changes in the $\mathrm{NF}-\kappa \mathrm{B}$ pathway may be partly caused by increased oxidative stress (28). It appears that increasing evidence suggests that ROS may mediate the activation of $N F-\kappa B$, which in turn stimulates the generation of inflammatory cytokines (29). To date, few studies have compared the activation of NF- $\kappa$ B with oxidative stress in obese asthmatics. In determining oxidative stress in the present study, the MDA concentrations were found to be significantly increased in the obese asthmatic mice, compared with the non-obese asthmatic mice. In addition, the elevation of MDA was positively correlated with
$\mathrm{NF}-\kappa \mathrm{B}$. However, no statistical difference was noted in MDA concentrations between the obese control group and normal control group, which was not in conformity with the changes in $\mathrm{NF}-\kappa \mathrm{B}$. The possible reason for this is that pathogens, cytokines, oxidants, growth factors and chemokines activate $\mathrm{NF}-\kappa \mathrm{B}$ through different mechanisms (30), and therefore, oxidative stress is only one of the important factors that is involved in the activation of NF- $\kappa \mathrm{B}$.

To date, few studies have been performed to investigate the correlation between the NF- $\mathrm{NB}$ signaling pathway and oxidative stress in the obesity-asthma association. The results of the present study indicated that oxidative stress was upregulated in the pulmonary tissues of asthmatic mice, and was positively correlated with the activation of the $N F-\kappa B$ signaling pathway in the lungs. In the obese asthmatic mice, the levels of oxidative stress and activation of $\mathrm{NF}-\kappa \mathrm{B}$ in the lung tissues were higher, compared with those in the non-obese asthmatic mice. It was hypothesized that oxidative stress induced tissue injury and activated the NF- $\kappa \mathrm{B}$ pathway, which enhanced the inflammatory reactions and, in turn, the inflammatory reactions may have enhanced the oxidative stress. This may explain the deterioration of symptoms in the obese asthmatic mice, compared with the non-obese asthmatic mice.

\section{Acknowledgments}

The authors would like to thank Professor Yang Zou (The Affiliated Hospital of Qingdao University), who contributed significantly to the present study. The authors would also like to thank Xianchang Sun, Wenwen Ran and Qunguan Wang for their technical assistance.

\section{References}

1. Novosad S, Khan S, Wolfe B and Khan A: Role of obesity in asthma control, the obesity-asthma phenotype. J Allergy (Cairo) 2013: 538642, 2013.

2. Mak JC, Ho SP, Ho AS, Law BK, Cheung AH, Ho JC, Ip MS and Chan-Yeung MM: Sustained elevation of systemic oxidative stress and inflammation in exacerbation and remission of asthma. ISRN Allergy 2013: 561831, 2013.

3. Ndisang JF, Vannacci A and Rastogi S: Oxidative stress and inflammation in obesity, diabetes, hypertension and related cardiometabolic complications. Oxid Med Cell Longev 2014: 506948, 2014.

4. Albuali WH: Evaluation of oxidant-antioxidant status in overweight and morbidly obese Saudi children. World J Clin Pediatr 3: 6-13, 2014.

5. Komakula S, Khatri S, Mermis J, Savill S, Haque S, Rojas M, Brown L, Teague GW and Holguin F: Body mass index is associated with reduced exhaled nitric oxide and higher exhaled 8-isoprostanes in asthmatics. Respir Res 8: 32, 2007.

6. Johnson JB, Summer W, Cutler RG, Martin B, Hyun DH, Dixit VD, Pearson M, Nassar M, Telljohann R, Maudsley S, et al: Alternate day calorie restriction improves clinical findings and reduces markers of oxidative stress and inflammation in overweight adults with moderate asthma. Free Radic Biol Med 42: 665-674, 2007.

7. Niederberger E and Geisslinger G: The IKK-NF-кB pathway: A source for novel molecular drug targets in pain therapy? FASEB J 22: 3432-3442, 2008.

8. Saldanha JF, Leal VdE O, Stenvinkel P, Carraro-Eduardo JC and Mafra D: Resveratrol: Why is it a promising therapy for chronic kidney disease patients? Oxid Med Cell Longev 2013: 963217, 2013.

9. Charokopos N, Apostolopoulos N, Kalapodi M, Leotsinidis M, Karamanos N and Mouzaki A: Bronchial asthma, chronic obstructive pulmonary disease and NF-kappaB. Curr Med Chem 16: 867-883, 2009. 
10. Lee YC, Lee KS, Park SJ, Park HS, Lim JS, Park KH, Im MJ, Choi IW, Lee HK and Kim UH: Blockade of airway hyperresponsiveness and inflammation in a murine model of asthma by a prodrug of cysteine, L-2-oxothiazolidine-4-carboxylic acid. FASEB J 18: 1917-1919, 2004.

11. Carlsen H, Haugen F, Zadelaar S, Kleemann R, Kooistra T, Drevon CA and Blomhoff R: Diet-induced obesity increases NF-kappaB signaling in reporter mice. Genes Nutr 4: 215-222, 2009.

12. Pierce GL, Lesniewski LA, Lawson BR, Beske SD and Seals DR: Nuclear factor- $\{$ kappa $\}$ B activation contributes to vascular endothelial dysfunction via oxidative stress in overweight/obese middle-aged and older humans. Circulation 119: 1284-1292, 2009.

13. Lee KS, Park HS, Park SJ, Kim SR, Min KH, Jin SM, Li L and Lee YC: An antioxidant modulates expression of receptor activator of NF-kappaB in asthma. Exp Mol Med 38: 217-229, 2006.

14. Li H, Ooi SQ and Heng CK: The role of NF- $\kappa \mathrm{B}$ in SAA-induced peroxisome proliferator-activated receptor $\gamma$ activation. Atherosclerosis 227: 72-78, 2013.

15. Holguin F and Fitzpatrick A: Obesity, asthma and oxidative stress. J Appl Physiol (1985) 108: 754-759, 2010.

16. Bowler RP and Crapo JD: Oxidative stress in allergic respiratory diseases. J Allergy Clin Immunol 110: 349-356, 2002.

17. Nadeem A, Chhabra SK, Masood A and Raj HG: Increased oxidative stress and altered levels of antioxidants in asthma. J Allergy Clin Immunol 111: 72-78, 2003.

18. Dut R, Dizdar EA, Birben E, Sackesen C, Soyer OU, Besler T and Kalayci O: Oxidative stress and its determinants in the airways of children with asthma. Allergy 63: 1605-1609, 2008.

19. Lessard A, Turcotte H, Cormier Y and Boulet L-P: Obesity and asthma: A specific phenotype? Chest 134: 317-323, 2008.

20. Kirkham $P$ and Rahman I: Oxidative stress in asthma and COPD Antioxidants as a therapeutic strategy. Pharmacol Ther 111: 476-494, 2006.

21. Mak JC, Leung H, Ho SP, Law BK, Lam WK, Tsang KW, Ip MS and Chan-Yeung M: Systemic oxidative and antioxidative status in Chinese patients with asthma. J Allergy Clin Immunol 114: 260-264, 2004
22. Ceylan E, Aksoy N, Gencer M, Vural H, Keles $\mathrm{H}$ and Selek S: Evaluation of oxidative-antioxidative status and the L-arginine-nitric oxide pathway in asthmatic patients. Respir Med 99: 871-876, 2005.

23. Smith LJ, Shamsuddin M, Sporn PH, Denenberg M and Anderson J: Reduced superoxide dismutase in lung cells of patients with asthma. Free Radic Biol Med 22: 1301-1307, 1997.

24. Cai D, Yuan M, Frantz DF, Melendez PA, Hansen L, Lee J and Shoelson SE: Local and systemic insulin resistance resulting from hepatic activation of IKK-beta and NF-kappaB. Nat Med 11: 183-190, 2005.

25. De Souza CT, Araujo EP, Bordin S, Ashimine R, Zollner RL, Boschero AC, Saad MJ and Velloso LA: Consumption of a fat-rich diet activates a proinflammatory response and induces insulin resistance in the hypothalamus. Endocrinology 146: 4192-4199, 2005.

26. Katiyar SK and Meeran SM: Obesity increases the risk of UV radiation-induced oxidative stress and activation of MAPK and NF-kappaB signaling. Free Radic Biol Med 42: 299-310, 2007.

27. Niederberger E and Geisslinger G: The IKK-NF-kappaB pathway: A source for novel molecular drug targets in pain therapy? FASEB J 22: 3432-3442, 2008.

28. Aljada A, Mohanty P, Ghanim H, Abdo T, Tripathy D, Chaudhuri A and Dandona P: Increase in intranuclear nuclear factor $\kappa \mathrm{B}$ and decrease in inhibitor kappaB in mononuclear cells after a mixed meal: Evidence for a proinflammatory effect. Am J Clin Nutr 79: 682-690, 2004

29. Yadav U and Ramana KV: Regulation of NF- $\kappa B$-induced inflammatory signaling by lipid peroxidation-derived aldehydes. Oxid Med Cell Longev 2013: 690545, 2013.

30. Grossmann M, Nakamura Y, Grumont R and Gerondakis S: New insights into the roles of ReL/NF-kappa B transcription factors in immune function, hemopoiesis and human disease. Int J Biochem Cell Biol 31: 1209-1219, 1999. 